\title{
THREE DOCUMENTATION SCENARIOS FOR THE LONG-TERM PRESERVATION OF DECORATED SURFACES IN THE CHURCH OF KUÑOTAMBO, PERU
}

\author{
M. Reina Ortiz ${ }^{1, *}$, E. Macchioni ${ }^{2}$, C. Cancino ${ }^{2}$, L. Rainer ${ }^{2}$, C. Vernaza ${ }^{3}$, A. Irco Nuñez ${ }^{4}$, S. Fai ${ }^{1}$, M. Santana Quintero ${ }^{1}$ \\ ${ }^{1}$ Carleton Immersive Media Studio (CIMS), Carleton University, Ottawa, Canada - \\ (miquel.reinaortiz, mario.santana, steve.fai)@cunet.carleton.ca \\ ${ }^{2}$ Getty Conservation Institute, Los Angeles, USA - \\ (emacchioni, ccancino, lrainer)@getty.edu \\ ${ }^{3}$ Conservator and consultant for Getty Conservation Institute, Monge, Swizerland - \\ c.vernaza@bluewin.ch \\ ${ }^{4}$ Dirección Desconcentrada de Cultura, Cusco, Peru - \\ andronicocusco@gmail.com
}

KEY WORDS: Decorated Surfaces, Mural Painting Conservation, Cultural Heritage Documentation, Heritage Record, Long-term Preservation, Monitoring, Documentation Scenarios

\begin{abstract}
:
The church of Santiago Apóstol of Kuñotambo is located in the southeast area of the Cusco province of Acomayo, containing remarkable interior mural paintings that contribute to the heritage value of the building and the area. The building was studied, conserved and seismically retrofitted as a model project for the Seismic Retrofitting Project (SRP), a collaborative project between the Getty Conservation Institute (GCI) and the Ministry of Culture of Peru in Cusco. Carleton Immersive Media Studio (CIMS) participated in the documentation of the decorated surfaces with an initial campaign in 2013, organized a series of workshops on documentation theory and practice with international experts and local professionals in 2017, and carried out a final recording after the conclusion of the site work in 2019. This last documentation phase provided a comprehensive documentation baseline and acquisition guidelines to plan the future long-term care of the decorated surfaces after their conservation. This paper presents the documentation carried out in 2019 and focuses on the three documentation scenarios proposed for the long-term preservation of decorated surfaces in the church: (1) Visual Documentation; (2) Digital Documentation; and (3) Comprehensive Digital Documentation. These different scenarios considered the particularly isolated location of the temple, the availability of equipment, the level of expertise in the different techniques proposed, and the frequency of future monitoring activities. Finally, the required tasks, necessary equipment, and potential challenges are presented for each of the documentation scenarios, with the objective being to offer a sustainable framework over time that serves the future Monitoring Plan for the heritage site.
\end{abstract}

\section{INTRODUCTION}

The church of Santiago Apóstol is the most prominent building in the rural village of Kuñotambo, located in the province of Acomayo, southeast of Cusco (Figure 1). Owned by the Roman Catholic Archbishopric of Cusco, it has been in continuous use since its construction in the $17^{\text {th }}$ century (Cancino and Lardinois, 2012). The church displays thick adobe walls over a rubble stone masonry, a wood-framed gable roof, and interior decorated surfaces. It was selected as a case study for the Seismic Retrofitting Project (SRP), a collaboration between the Getty Conservation Institute (GCI) and the Ministry of Culture of Peru in Cusco, due to its architectural and decorated features, representative of the typology of religious buildings constructed in the region of the Andes during the Spanish Viceroyalty, and of their characteristic structural modes of failure. The study of the church, together with three other building prototypes, aims to scientifically demonstrate the applicability of traditional techniques using local materials and expertise for the seismic retrofitting of earthen buildings in Peru and South America (Getty, n.d.).

Recommendations for the seismic retrofit of the church were defined during the investigation phase of the SRP. Between 2016 and 2019, the Ministry of Culture of Peru in Cusco collaborated with the GCI and various consultants to define the technical specifications of the project and implement the conservation and seismic retrofitting works (Cancino et al., 2020). The retrofitted church was inaugurated in June 2019 and officially delivered to its owner, the Archbishopric of Cusco. The SRP team, together with Peruvian partners and local stakeholders, is currently developing a Monitoring and Maintenance Plan for the site to ensure its long-term sustainable preservation.

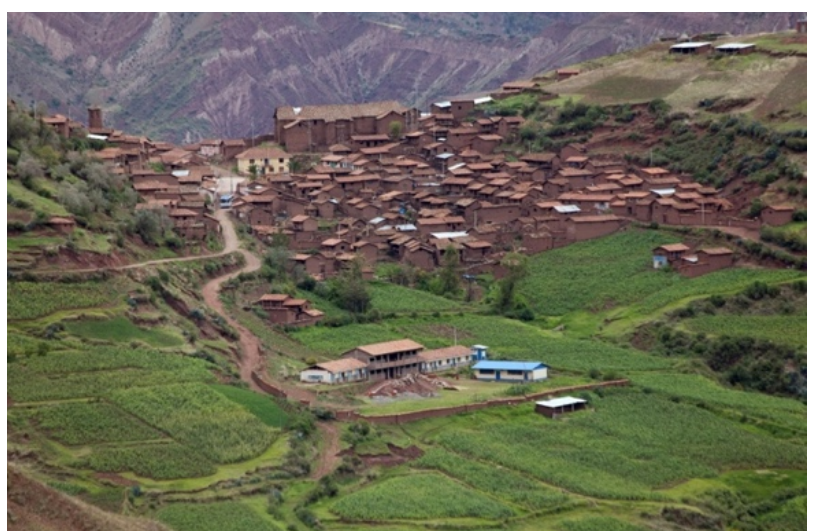

Figure 1. View of the village of Kuñotambo, showing the church of Santiago Apóstol and the bell tower before the intervention.

Photograph by Scott Warren (C) GCI 2011. 


\subsection{Mural Paintings in the Church of Kuñotambo}

The term 'decorated architectural surfaces' refers to any construction element which has painted decoration, gilding, or carved, sculpted or applied decorative elements or techniques. The church of Kuñotambo is decorated with mural paintings on structural walls, two columns and ceiling under the choir loft with painted decoration, and a painted and gilded pulpit and altarpiece or retablo. In this paper, we focus on the mural paintings on the interior wall surfaces of the nave and presbytery of the church (Figure 2). They include figures of saints and evangelists within painted frames, a horizontal frieze with cherubs, fruits, vegetables, geometric and architectural patterns, and draperies (Figure 3). It is possible to recognize the influence of European paintings and there are many similarities with other churches of the region. They are painted $a$ secco, a mural painting technique executed on dry plaster using pigments with an organic binder. At Kuñotambo, the mural paintings were executed using pigments mixed with an animal binder over a thin gypsum layer; this fine layer was laid over a mud plaster render, covering the adobe walls of the church. Additional information can be found in Vernaza et al. (2018). The presence and characteristics of the decorated surfaces greatly contribute to the significance of the site. For this reason, the fieldwork in 2019 focused on recording the condition of the mural paintings after conservation and the planning of future monitoring. The documentation of the mural paintings acknowledges the importance of considering the multiscale documentation of decorated surfaces (Reina et al., 2019) that takes into consideration the importance of three-dimensional stratigraphy as well as time - the fourth dimension of wall paintings (Cather, 1992; Cather, 2010)

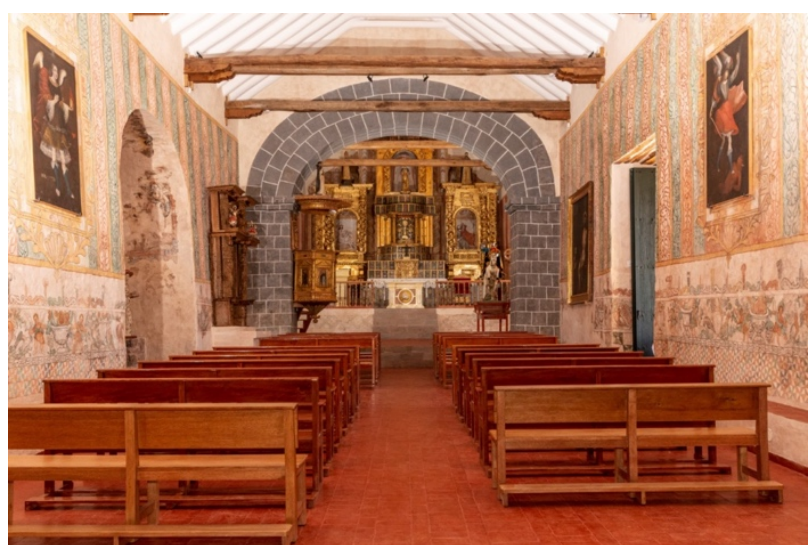

Figure 2. Interior view of the church after its conservation. Photograph by Anna Flavin (C) GCI 2019.

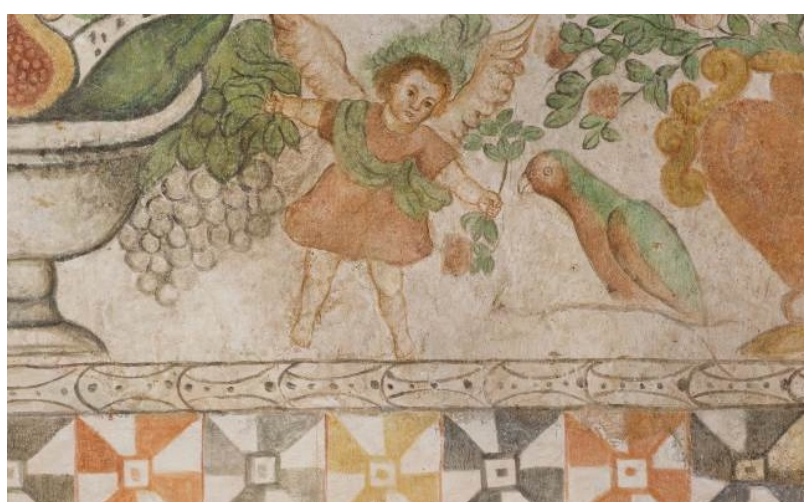

Figure 3. Mural painting detail of the south wall of the nave. Photograph by CIMS C GCI 2019.

\section{RECORDING KUÑOTAMBO MURAL PAINTINGS}

Documentation of the mural paintings of the church was pivotal during the research phase, and was considered necessary for the post-intervention phase. CIMS carried out a first recording of the mural paintings of the church in 2013 that consisted of a topographical survey and a photogrammetric project. This documentation was essential to create a baseline for the future development of the assessment, consolidation, cleaning and interpretation of the church mural paintings.

During the consolidation, cleaning and interpretation works in 2017, CIMS organized a series of workshops addressing heritage recording theory and practice, focusing specifically on the documentation of decorated surfaces and the technique of photogrammetry. These workshops were aimed at professional staff from the Ministry of Culture of Peru in Cusco to ensure they could proficiently carry out the documentation of similar sites in the region.

After the conservation and seismic retrofitting works were completed, there was a need to document the site again to provide a baseline for the monitoring activities and the long-term care of the church (Figure 4). A recording campaign was carried out at the end of 2019 and included the urban context of the church (Figure 5), the building (Figure 6) and the mural paintings (Figure 7). Additionally, CIMS collaborated with the wall painting conservators of the SRP team and the Ministry of Culture of Peru in Cusco to prepare guidelines for the acquisition and processing of data that would allow them to compare subsequent datasets generated in future monitoring activities.

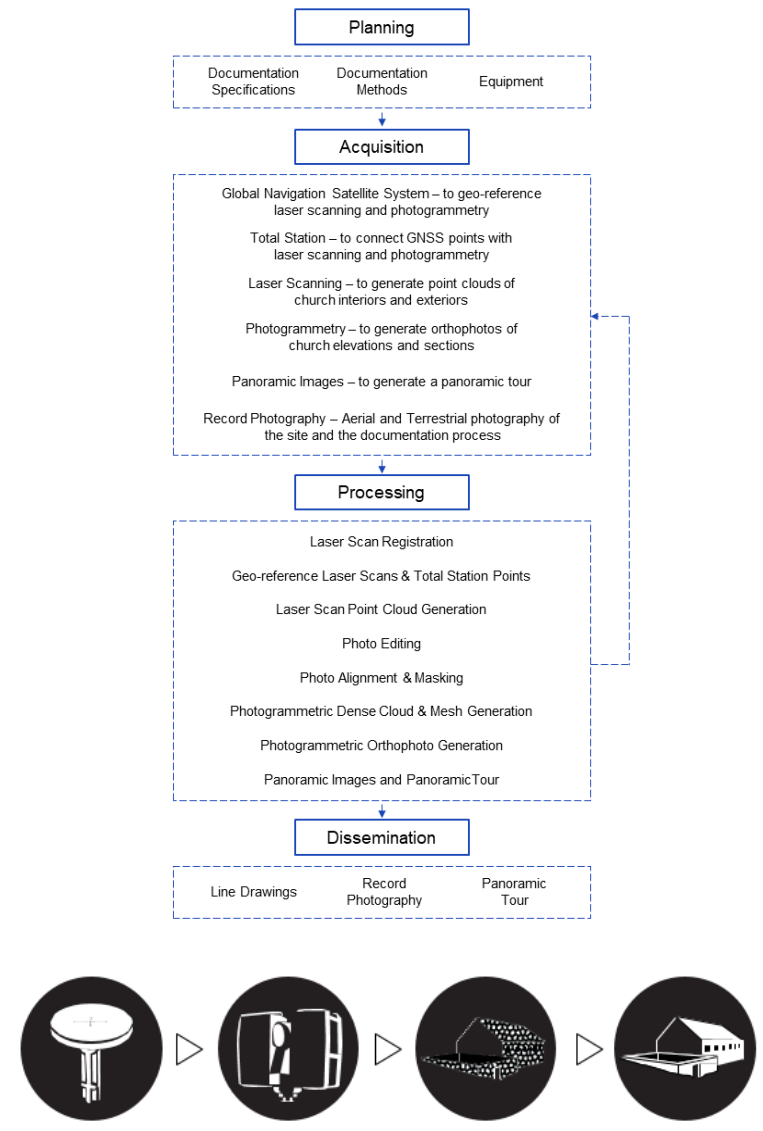

Figure 4. Documentation project workflow (planning, acquisition, processing, dissemination) Diagram by CIMS (C) GCI 2019. 


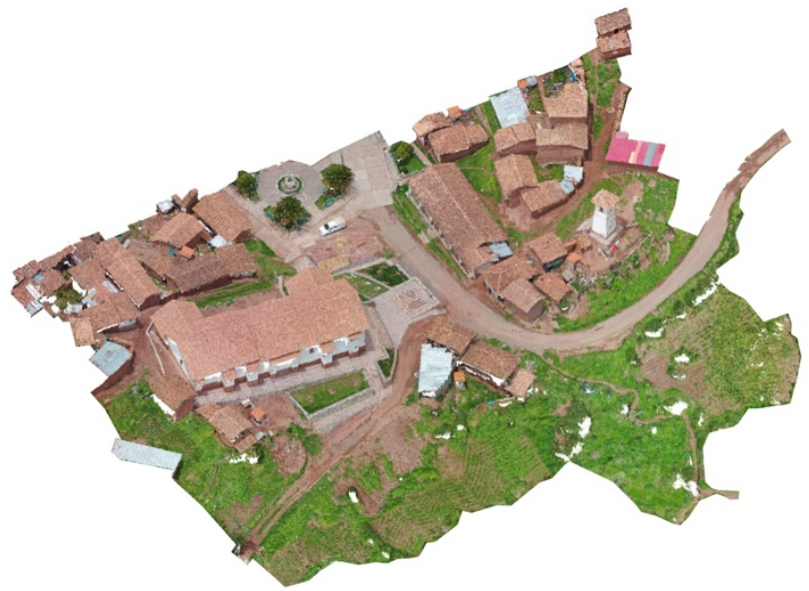

Figure 5. Aerial photogrammetry of Kuñotambo. Image by CIMS (C) GCI 2019.

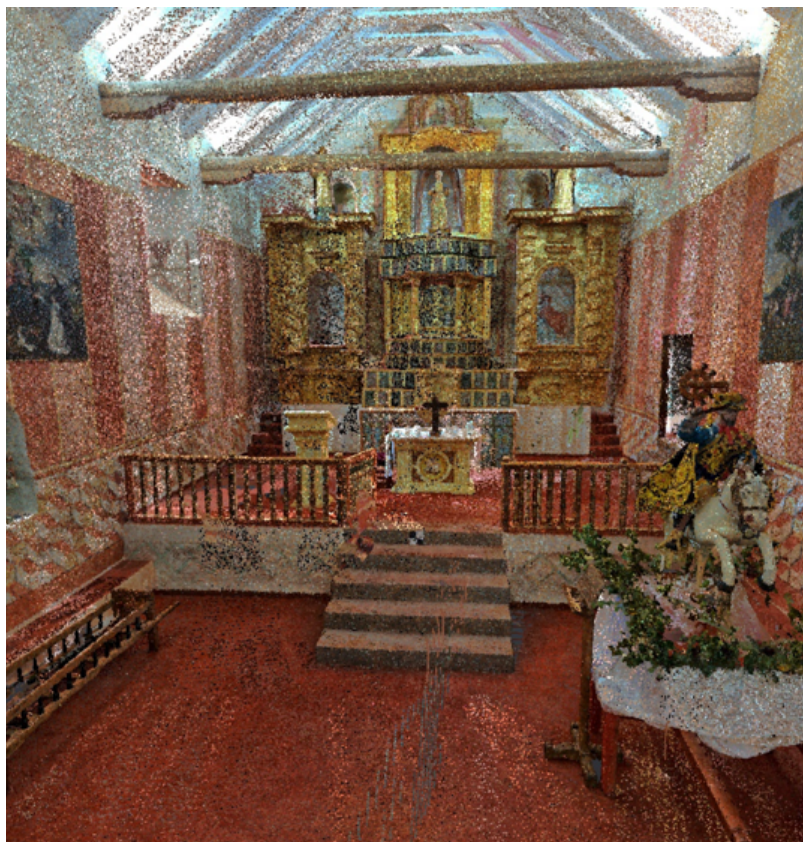

Figure 6. Consolidated interior Point Cloud of the church. Image by CIMS (C) GCI 2019.
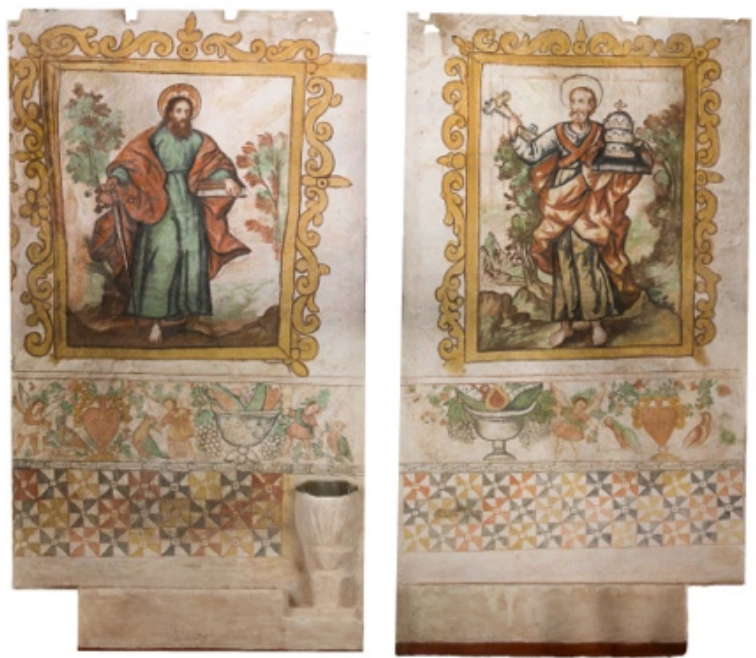

Figure 7. Detailed terrestrial photogrammetry of the mural paintings in the area below the choir loft. Image by CIMS (C) GCI 2019.

\subsection{The Geodetic Network: A Combination of Fixed and Natural Control Points.}

During the 2019 campaign, the CIMS team set up a geodetic network measured using a Reflectorless Electronic Distance Measurement (REDM) Total Station Leica Geosystems model Viva TS11 in the inside and immediate surroundings of the outside of the church. This made it possible to combine all the different datasets generated (3D Laser Scanning, aerial and terrestrial photogrammetry) in the same survey network and allow future campaigns to use it as reference. The geodetic network was comprised of fixed control points on the ground and natural control points on the mural paintings (Figure 8). These two types of control points generated a robust and permanent survey network on the ground from which to measure the mural paintings and use them as a reference for future campaigns.

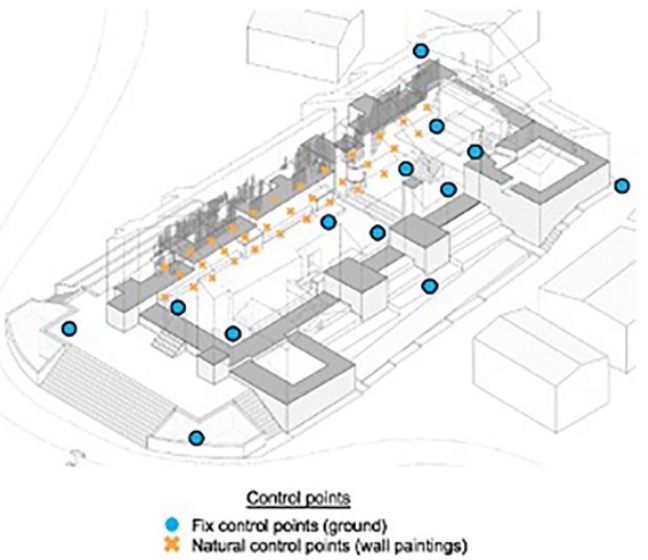

Figure 8. Fixed and natural control points (geodetic network). Diagram by CIMS (C) GCI 2019.

The fixed control points on the ground used metal screws drilled to a solid surface and fixed with epoxy to ensure their position over time. The placement of each of the points was discussed and agreed upon between the SRP team and Ministry of Culture staff, inserting all the fixed points in stable and non-historic areas. For the post-intervention documentation of the mural paintings on the interior of the church, and in order to not to damage their historic fabric, natural and easily recognizable control points such as frame corners or bird beaks were surveyed. For each of the fixed and natural control points, a witness sheet (Figure 9 and 10) was provided that detailed the Ground Control Point (GCP) number, the coordinates, a description of the location, a contextual photograph and a detailed photograph, and general information on the project (project, date, survey point, and source).

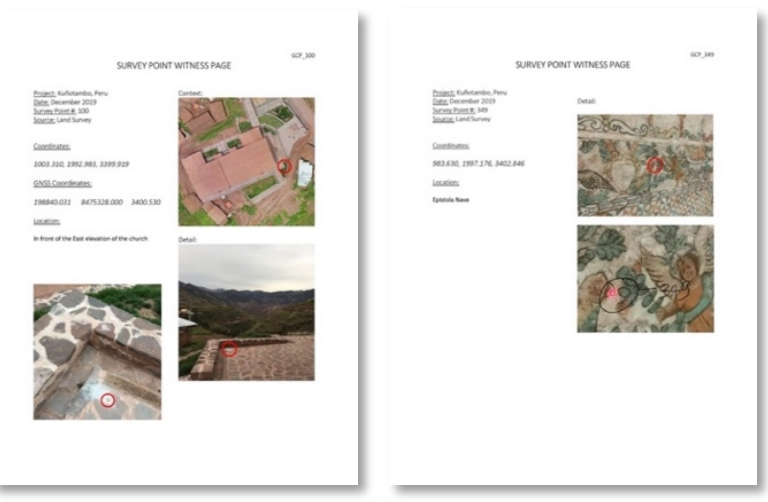

Figure 9-10. Witness Sheets (fixed GCP 100/natural GCP 349). Images by CIMS C GCI 2019. 


\subsection{Mural Paintings Recording and Processing}

After discussion with the SRP team, CIMS determined that close range photogrammetry (Figure 11) was appropriate to capture the desired level of detail for the mural paintings. One of the major challenges of the photogrammetric project was obtaining an adequate and even distribution of light during the photographic acquisition due to the height of the interior church walls $(7 \mathrm{~m}$ height).

The available scaffolding did not allow sufficient mobility to develop the project within the available timeframe. Accordingly, it was decided to implement a two-way capturing approach:

1. Main spaces would be captured using the available artificial and natural lighting; and,

2. Bottom and specific areas would be captured using a set of two flashes per camera mounted on tripods to control lighting and get homogeneous exposure.

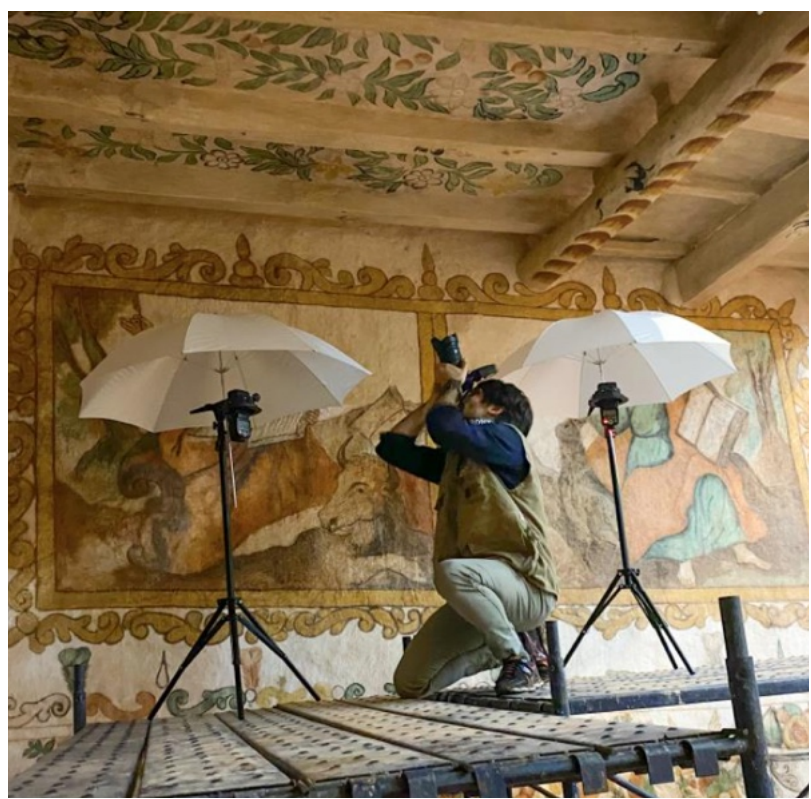

Figure 11. Recording of decorated surfaces with scaffolding, flashes, and light-diffusors below the choir loft. Photograph by CIMS @ GCI 2019.

To cover all painted surfaces, a sequence overlapping images was captured in each pre-defined sector using a full frame Sony Mirrorless $\alpha 7 \mathrm{R}$ IV Camera. The camera featured a $24 \mathrm{~mm}$ mounted lens that allowed photographs to be taken with controlled radial distortion while achieving a resolution of $61 \mathrm{MP}$ and an effective Ground Sample Distance (GSD) of 0.20-0.35 $\mathrm{mm}$. This process estimates the camera-to-surface distance and baseline distance required between the overlapping images to obtain the desired quality of images (Table 1).

\begin{tabular}{|l|l|l|}
\cline { 2 - 3 } \multicolumn{1}{c|}{} & $\begin{array}{l}\text { Main } \\
\text { Space }\end{array}$ & $\begin{array}{l}\text { Bottom and } \\
\text { Specific Areas }\end{array}$ \\
\hline Sensor Width (mm) & 35.7 & 35.7 \\
\hline Focal length (mm) & 50 & 24 \\
\hline Distance to the surface (m) & 4.5 & 1 \\
\hline Image width (pixels) & 9504 & 9504 \\
\hline GSD (mm) & 0.35 & 0.20 \\
\hline
\end{tabular}

Table 1. GSD calculations for terrestrial photogrammetry. Table by CIMS C GCI 2019.
It was important to ensure that the photogrammetric models correctly represented the mural paintings. The use of an X-Rite ColorChecker Passport allowed for consistent, repeatable capture of the decorated surfaces. The ColorChecker was used to create a profile for the camera in the specific lighting conditions, correct the exposure, and correct the white balance (Figure 12).

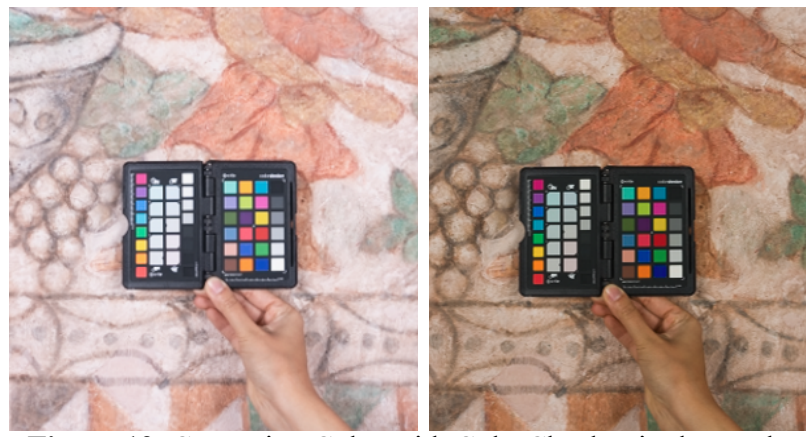

Figure 12. Correcting Color with ColorChecker in the north wall of the nave. Images by CIMS C GCI 2019.

Finally, the photogrammetric model was generated using Agisoft Metashape and geo-referenced to the survey network using the fixed and natural control points measured previously with the REDM Total Station (Figure 13). In parallel with the photogrammetric process, the exterior and interior of the church were documented with a terrestrial 3D Laser Scanner Faro Focus $3 \mathrm{D}$ that generated a Point Cloud with a density of at least $6 \mathrm{~mm}$ between each point. This dataset was the primary source to elaborate the architectural drawings of the building, and was also used to verify the alignment of the photogrammetric project.
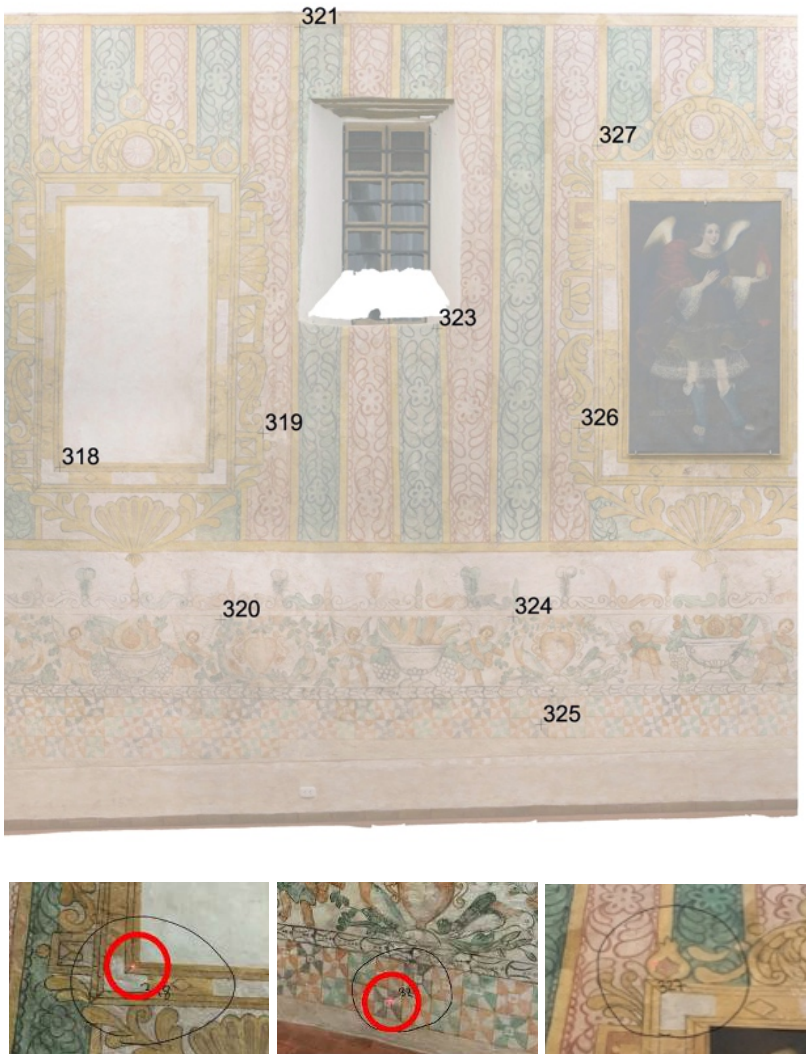

Figure 13. Upper: Samples of natural control points of the geodetic network on one section of the mural paintings and marked on the ortho-corrected image. Lower: Three reference images of the natural point locations GCP 318,325 , and 327. Images by CIMS C GCI 2019. 


\section{THREE DOCUMENTATION SCENARIOS FOR THE LONG-TERM PRESERVATION OF KUÑOTAMBO MURAL PAINTINGS}

The heritage record created after the conclusion of the work will become the baseline for subsequent activities aimed at the longterm preservation and monitoring of the site and its mural paintings. CIMS created three documentation scenarios that could be used to evaluate the decorated surfaces over time. These scenarios take into account different ranges of skill level, equipment, time, and availability of the actors who might be involved in this task. This will allow the team continuing the work on the church to choose an evaluation scenario that fits their needs and skill level.

This paper presents each of these three scenarios, introducing the required skills and equipment. It also presents the tasks that are involved and the main challenges. The following are the three documentation scenarios proposed:

1. Scenario 1: Visual Documentation;

2. Scenario 2: Digital Documentation with Photogrammetry and Manual or REDM Total Station Survey; and,

3. Scenario 3: Comprehensive Digital Documentation with Photogrammetry, 3D Laser Scanning, and REDM Total Station Survey.

These scenarios will be considered by the SRP team, the Peruvian partners and local stakeholders when defining activities and specific protocols to be included in the Monitoring Plan for the site (Macchioni et al., forthcoming).

\subsection{Scenario 1: Visual Documentation}

This first scenario, "Visual Documentation," (Figure 14) requires minimal investment in time and equipment and is considered appropriate for the monitoring activities that occur more frequently; however, professionals with specific knowledge in wall painting conservation are required. This scenario involves the following tasks:

- Carry out an assessment of the mural paintings through visual inspection, identifying and marking conditions on the printed line drawings with ortho-photography of the mural paintings generated in the heritage documentation report in 2019 (Figure 14); and,

- Based on the documentation collected on-site, update the existing raster images (.jpeg) and/or vector (.dwg) with changes identified with comments or drawings.
The equipment required to develop this scenario is:

- Printed heritage report; and,

- Set of tracing paper, notebook and drawing tools.

The task outlined in this scenario is the simplest and the one that requires the least equipment. The assigned team must regularly inspect the mural paintings to identify changes that might compromise their condition in the future. The following requirements must be taken into account:

- New metric data to reference/measure deformations or movements is not recorded;

- The accuracy of colour calibration (RGB for digital image) and CMYK (printed documents) is not equivalent; and,

- Consistency of interpretation might be different depending upon the judgement of the professionals carrying out the assessment.

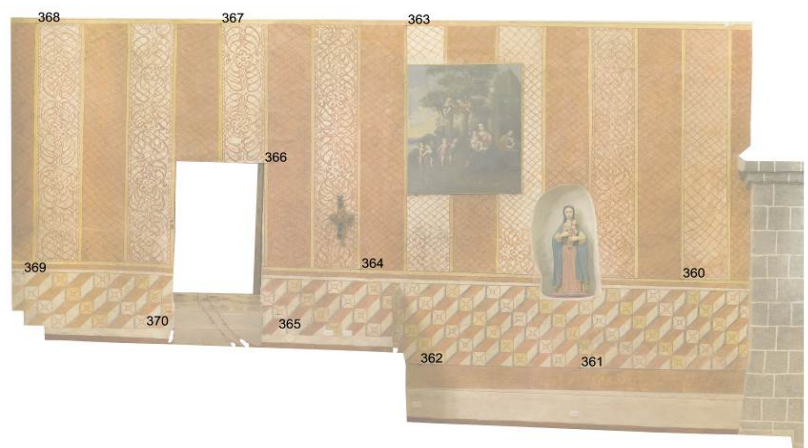

Figure 15. Ortho-corrected image used as a reference in Scenario 1. Image by CIMS (C) GCI 2019.

\subsection{Scenario 2: Digital Documentation with Photogrammetry and Manual or REDM (Total Station) Survey}

This second scenario, "Digital Documentation," entails a modest investment in time and equipment, including hiring skilled professionals in the field of photogrammetry. It requires a photographic DSLR camera and measuring tools. Its main objective is to obtain detailed documentation of the selected monitoring locations and the rest of the mural paintings with metric data. Since having available a REDM Total Station and trained personnel might be a challenge, this scenario contemplates two options that are explained below: reference the photogrammetric projects to the existing network with a manualor a REDM Total Station survey. This scenario involves the following tasks:

- Acquire new metric data by manual measurement procedures (e.g. measuring tape or Laser Distance Measurer (LDM)) or with a REDM Total Station using known reference point (fixed and/or natural);

- Reference the new measurements to the existing fixed control points of the geodetic network for comparison;

- Reproduce the previous photogrammetric project (camera specifications and light conditions) to generate a new model of the selected areas (elevation/coloured model, textured mesh); and,

- Based on the documentation collected on-site, update the existing raster (.jpeg) and/or vector (.dwg) images with changes identified using comments or drawings.

Figure 14. Scenario 1: Visual documentation. Image by CIMS @ GCI 2019. 
The equipment required to develop this scenario is:

- Printed heritage report;

- Set of tracing paper, notebook and drawing tools;

- Measuring tape, LDM, and/or REDM Total Station;

- DSLR Camera; and,

- Photogrammetric equipment (flash, light diffusers and/or scaffolding).

If the measurements are taken manually or with an LDM (Figure 16), there is no need to have personnel trained to use a REDM Total Station. However, the following conditions must be taken into account:

- Precision and speed of metric data acquisition by manual procedures;

- Difficult to precisely determine the surface movement;

- Direct measurements might be challenging without scaffolding, and the use of measuring tape might produce damage to the surface; and,

- Need to triangulate all the existing fixed and natural points to see if any deviations happen over time (Figure 17).

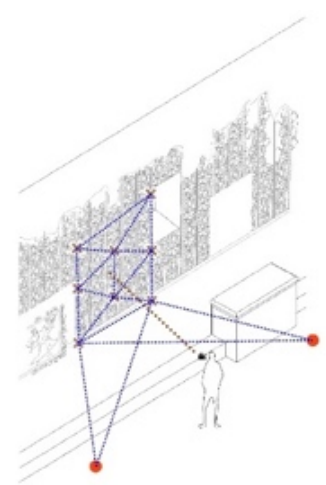

Figure 16. Scenario 2: Photogrammetric project with manual survey. Image by CIMS C GCI 2019.

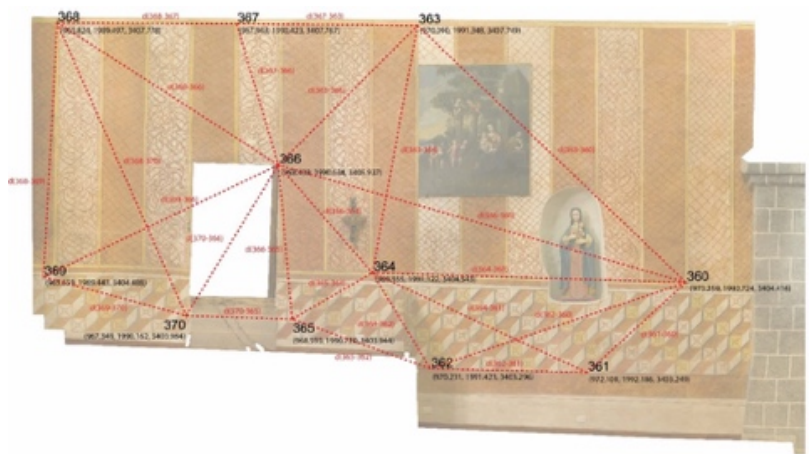

Figure 17. Ortho-corrected image used as a reference to triangulate measurements in Scenario 2. Image by CIMS (C) GCI 2019.

If the measurements are taken digitally with a REDM Total Station (Figure 18), this requires a more substantial investment of time and equipment and the involvement of a geomatics expert, along with wall painting conservators. The advantage is that this system generates precise metric positions (Figure 19) that will be easy to compare with the previous records. However, the following requirements must be taken into account:
- Need for expert personnel trained in geomatics and availability of equipment;

- Precision in the use of the REDM Total Station to reference the existing fixed control points; and,

- Knowledge of how to process the data obtained from REDM Total Station.

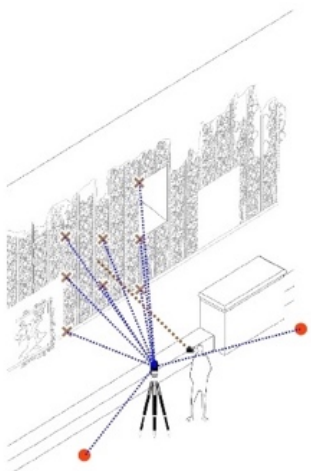

Figure 18. Scenario 2: Photogrammetric project with REDM Total Station survey. Image by CIMS (C GCI 2019.

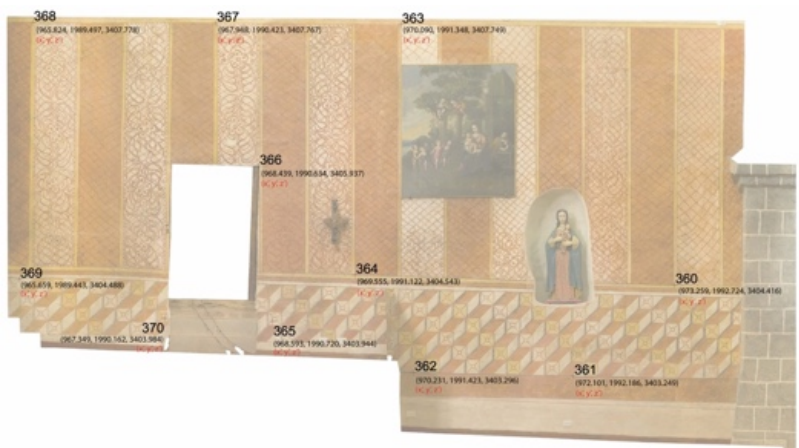

Figure 19. Ortho-corrected image used as a reference to compare $\mathrm{x}, \mathrm{y}$, and $\mathrm{z}$ coordinates of GCPs in Scenario 2. Image by CIMS (C) GCI 2019.

3.3 Scenario 3: Comprehensive Digital Documentation with Photogrammetry, 3D Laser Scanning, and REDM Total Station

This last scenario, "Comprehensive Digital Documentation," (Figure 20) requires a significant investment and the hiring of a geomatics and 3D Laser Scanner expert, along with wall painting conservators. It requires a REDM Total Station, a 3D Laser Scanner device and, a DSLR camera. Its main objective is to produce a detailed documentation of the whole building and surroundings along with a detailed documentation of the selected monitoring locations and the rest of the mural paintings with precise metric positioning. It involves the following tasks:

- Acquire new metric data with a REDM Total Station using known reference points (fixed and/or natural);

- Reference the new measurements to the existing fixed control points of the geodetic network for comparison;

- Reproduce the previous photogrammetric project (camera specifications and light conditions) to generate a new model of the selected areas (elevation/coloured model, textured mesh);

- Generate the building and context Point Cloud using 3D Laser Scanner; and,

- Based on the documentation collected on-site, update the existing raster (.jpeg) and/or vector (.dwg) images with changes identified using comments or drawings. 
The equipment required to develop this scenario is:

- Printed heritage report;

- Set of tracing paper, notebook and drawing tools;

- REDM Total Station;

- DSLR Camera;

- Photogrammetric equipment (flash, light diffusers and/or scaffolding); and,

- 3D Laser Scanner.

The tasks outlined in this scenario require expertise in geomatics, photogrammetry and 3D Laser Scanning. This task is meant to verify the state of the building in the long term, placing attention on structural deformations that might affect the integrity of the mural paintings. The following requirements must be considered:

- New metric data to reference/measure deformations or movements should be recorded in relation to the existing survey;

- If the photogrammetric and scanner projects are reproduced following the guidelines, it is possible to have similar datasets to compare geometry and surface colour modifications; and

- This scenario requires expensive equipment and technical knowledge.

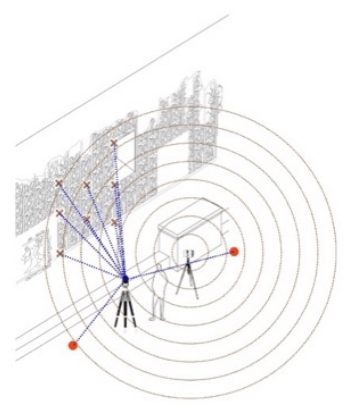

Figure 20. Scenario 3: Comprehensive Digital Documentation with Photogrammetry, 3D Laser Scanning, and REDM Total Station. Image by CIMS C GCI 2019.

\section{COMPARISON OF FUTURE ACQUIRED DATA}

One of the objectives that drove the documentation campaign of 2019 was to generate a comprehensive documentation of the building that could be used as a reference for future monitoring at the different architectural scales mentioned before: context, building, and mural paintings. The introduction of fixed points made it possible to create a survey network to reference new datasets created with the objective of comparison with the generated data.

Regardless of the documentation scenario chosen, all the documents generated, either visual or digital, can be referenced to the existing network and existing documents (ortho-corrected images, photogrammetric models, or 3D Laser Scanning) to compare the documentation over time. In other words, if different datasets of Point Clouds are produced at different times, it is possible to compare them to see how the geometry has changed. For example, CloudCompare's workflow 'How to compare two 3D entities' (CloudCompare, 2015) can be used for comparing dense point clouds and meshes.

\section{CONCLUSIONS}

CIMS collaborated with the GCI SRP team, Peruvian partners and local stakeholders in different phases of the documentation of the decorated surfaces, with particular attention to the mural paintings in the church of Kuñotambo. In addition to recording the site after the conclusion of the works in 2019, CIMS defined three possible documentation scenarios for the post-treatment monitoring. The three suggested scenarios-considering tasks, equipment, and challenges - seek the appropriate use of the various tools and techniques involved during the documentation process, considering the peculiarities of the site and its caretakers. The main objective of this paper is not to introduce novel digital technologies but to offer a sustainable documentation framework that considers the participation of professionals with different expertise and skills levels and with different timeframes and equipment availability. In fact, the various scenarios accommodated different needs while preserving the final quality of the documentation task. This documentation framework did not exist in Peru, and SRP project partners intend to apply this process in other historic churches with wall paintings.

The outlined scenarios were considered in the definition of activities and specific protocols that will be part of the Monitoring Plan for the site, including assessing its structural and architectural elements and its decorated surfaces or mural paintings (Macchioni et al., forthcoming).

\section{ACKNOWLEDGEMENTS}

CIMS project team would like to acknowledge the GCI, the Ministry of Culture of Peru in Cusco (Dirección Desconcentrada de Cultura Cusco), the Archbishopric of Cusco, the community of Kuñotambo, and other Peruvian stakeholders for the opportunity to collaborate on this project for the conservation of the church of Santiago Apóstol in Kuñotambo. Finally, we want to thank all individuals and institutions that, in one way or another, helped with the completion of this work.

\section{REFERENCES}

Cather, S. ed., 1992. The Conservation of Wall Paintings: Proceedings of a Symposium Organized by the Courtauld Institute of Art and the Getty Conservation Institute, London, July 13-16, 1987. Getty Publications.

Cather S., 2010. "Choices and Judgment: The Professional Conservator at the Interface." Conservation of Ancient Sites on the Silk Road, Proceedings of the Second International Conference on the Conservation of Grotto Sites, Mogao Grottoes, Dunhuang, People's Republic of China, June 28-July 3, 2004, The Getty Conservation Institute, Los Angeles, 2010:22-32.

Cancino, C., Lardinois, S., 2012. Seismic Retrofitting Project: Assessment of Prototype Buildings. Getty Conservation Institute, Los Angeles.

Cancino, C., Macchioni, E., Marcus, B., Mellado, J. C., Menéndez, J. C., 2020. "Seismic retrofitting using local materials and expertise at a church in Kuñotambo, Peru." APT Bulletin, $51(2 / 3), 23-30$. 
CloudCompare Development Team, 2015. https://www .cloudcompare.org/doc/wiki/index.php?title= How_to_compare_two_3D_entities (21 April, 2021)

Getty, n.d. Seismic Retrofitting Project. https://www.getty.edu/conservation/our_projects/field_projects/ seismic/index.html (2 April 2021).

Macchioni E., G. Karanikoloudis, P. B. Lourenço, J. C. Mellado Flores, C. Miranda Sotomayor, V. S. Paliza Flores, L. Rainer, M. Reina Ortiz, M. Santana Quintero, C. Vernaza, C. Cancino., forthcoming. "Construyendo el cuidado a Largo Plazo: Plan de Monitoreo Multidisciplinario para el Templo de Kuñotambo, Perú = Building Long-Term Care: Multi-disciplinary monitoring plan for the Church of Kuñotambo, Peru." In Proceedings of TERRA 2022 International Conference, Santa Fe, New Mexico.

Reina Ortiz, M., A. Weigert, A. Dhanda, C. Yang, K. Smith, A. Min, M. Gyi, S. Su, S. Fai, and M. Santana Quintero., 2019. “A Theoretical Framework for Multi-scale Documentation of Decorated Surfaces." ISPRS - International Archives of the Photogrammetry, Remote Sensing and Spatial Information Sciences, XLII-2/W15 (August): 973-80.

Vernaza, C., Cancino, C., Rainer, L., 2018., Proyecto de Estabilización Sismorresistente: Informe sobre el análisis de condiciones, diagnóstico y pruebas de protección para las pinturas murales-Templo Santiago Apóstol de Kuñotambo. Getty Conservation Institute, Los Angeles. 